\title{
The Effect of Rhythmic Breathing on the Severity of Sternotomy Pain after Coronary Artery Bypass Graft Surgery: A Randomized Controlled Clinical Trial
}

\author{
Hassan Babamohamadi ${ }^{\mathbb{D}},{ }^{1,2}$ Masoumeh Karkeabadi $\left(\mathbb{D},{ }^{3}\right.$ and Abbasali Ebrahimian $\mathbb{I D}^{1,4}$ \\ ${ }^{1}$ Nursing Care Research Center, Semnan University of Medical Sciences, Semnan 3513138111, Iran \\ ${ }^{2}$ Department of Nursing, Faculty of Nursing and Midwifery, Semnan University of Medical Sciences, Semnan 3513138111, Iran \\ ${ }^{3}$ Student Research Committee, Semnan University of Medical Sciences, Semnan 3513138111, Iran \\ ${ }^{4}$ Emergency Medicine Group, School of Medicine, Qom University of Medical Sciences, Qom, Iran
}

Correspondence should be addressed to Abbasali Ebrahimian; ebrahimian.aa@gmail.com

Received 18 March 2021; Revised 4 May 2021; Accepted 31 May 2021; Published 11 June 2021

Academic Editor: Wei Lei

Copyright ( $\odot 2021$ Hassan Babamohamadi et al. This is an open access article distributed under the Creative Commons Attribution License, which permits unrestricted use, distribution, and reproduction in any medium, provided the original work is properly cited.

\begin{abstract}
Background. Moderate-to-severe pain is reported in up to $75 \%$ of the patients in the first 48 hours after cardiac surgery. Evidence suggests that distraction is an effective nursing intervention for controlling short-term and transient pain. Distraction can be achieved by various techniques, including progressive muscle relaxation, meditation, and rhythmic breathing (RB). The present research aimed at evaluating the impacts of RB on the severity of sternotomy pain after Coronary Artery Bypass Graft (CABG). Methods. This randomized, controlled clinical trial was conducted on 60 patients after CABG surgery at the open-heart surgery Intensive Care Unit (ICU) of Kowsar Hospital, affiliated to Semnan University of Medical Sciences in Semnan, Iran. The patients were selected through convenience sampling and randomly assigned to two groups, including (1) intervention or RB and (2) control groups. RB was performed in the intervention group every 12 hours ( 9 a.m. and 9 p.m.) for three consecutive days after the surgery. The control group received only routine care for pain control (opioid analgesics) with no additional interventions. The severity of pain was measured every day in both groups of patients before and after the interventions using the Visual Analog Scale (VAS). Results. The mean postintervention pain scores were significantly different from the mean preintervention scores in the intervention group $(p<0.05)$. The changes in the mean pain score in the intervention group were also significantly different from the corresponding changes in the controls $(p<0.05)$. Conclusion. Based on the results, the severity of pain after the intervention was significantly lower in the RB group compared to the control. RB was found to be an effective technique for reducing the patients' pain and is therefore recommended as a post-CABG pain control technique. Iranian Registry of Clinical Trials: this trial is clinically registered with IRCT20120109008665N7, registered 3 September 2018.
\end{abstract}

\section{Introduction}

Open-heart surgery is currently performed in many countries to increase the survival and quality of life of patients with cardiac diseases [1]. Coronary Artery Bypass Graft (CABG) is the most common open-heart surgery in the US with 156,931 cases in 2016, which shows an increase of $6.1 \%$ compared to the preceding four years, and $63 \%$ of them were nonelective [2]. In Iran, over 30,000 open-heart surgeries are performed in different medical centers every year [3], of which $60 \%$ are CABG [4]. Despite being a successful cardiac treatment, heart surgery is still a traumatic event that can lead to a wide range of complications, including severe pain in the surgery site, stroke, pulmonary edema, pericarditis, and postsurgery depression [5-9].

Several factors contribute to the pain following openheart surgery, including sternotomy, harvesting saphenous vein, harvesting internal thoracic artery, and inserting various drains [10]. The patients' pain can prevent their effective coughing, deep breathing, and cooperation in 
physiotherapy; cause the retention of pulmonary secretions; and lead to complications such as pulmonary atelectasis, pneumonia, and respiratory failure $[11,12]$. By stimulating the sympathetic nervous system and raising epinephrine and norepinephrine levels, pain can also increase cardiac workload, create an imbalance in oxygen supply and demand, and consequently lead to ischemia and myocardial infarction [13]. Improper pain control after cardiac surgery can cause a high incidence of Poststernotomy Pain Syndrome (PSPS) [14]. PSPS is hard to treat and affects the quality of life of the patients and their relatives in the long term [15-17].

According to medical personnel, patients are not in great pain after sternotomy because the tissue damage that occurred is negligible and the patients are minimally mobile after surgery. Nevertheless, Lahtinen reported moderate-tosevere pain (pain score of 4 to 10 ) in up to $75 \%$ of the patients in the first 48 hours after cardiac surgery [18]. Thus, effective pain management will result in faster recovery, reduced postsurgery complications and length of stay, and increased patient satisfaction.

A variety of medicinal and nonmedicinal therapies have been proposed for pain management. Medicinal methods such as opioids are currently used to alleviate pain in cardiac patients but are not desirable as the first line of treatment because of their costs and adverse effects on different body parts, which increase patient mortality and morbidity [19]. Hence, nonmedicinal pain control interventions are preferred because they reduce the need for medications [20]. As such, various nursing measures have been used as Complementary Therapy Methods (CTM) to help patients [21, 22].

Studies indicate that distraction is an effective nursing intervention for controlling short-term and transient pain by increasing endorphins [23, 24]. Quoting several studies, Malloy and Milling reported distraction as one of the oldest psychological interventions for pain relief with remarkable effects [25]. By balancing the anterior and posterior hypothalamus and reducing the activity of the sympathetic nervous system and the secretion of catecholamine, distraction can mitigate stress-induced muscle tension and physiological side-effects such as hypotension, heart rate, and muscular spasms [26]. Another advantage of distraction in clinical settings is that patients can perform this technique independently. Thus, in combination with analgesics, it provides comprehensive pain relief. Distraction can be achieved by various techniques, including progressive muscle relaxation, mandibular relaxation, meditation, and rhythmic breathing (RB) [27].

$\mathrm{RB}$ is one of the distraction methods that make patients voluntarily distract themselves from a painful stimulus and thus help control their pain [28, 29]. Distraction is based on the idea that, with diverse and sufficient sensory stimuli, the reticular formation in the brainstem can choose to inhibit or ignore the transmission of such feelings as pain [30]. In this technique, the perception of pain is minimized through distraction-induced reduced alertness [31]. Moreover, RB mitigates pain, anxiety, and stress by increasing the activity of the parasympathetic nervous system via the vagus nerve and increasing the inhibitory function of the Gamma-
Aminobutyric Acid (GABA) receptors in the brain pathways that are vital to perceiving fear, emotional regulation, and stress response. The advantages of using this technique include its simplicity, low costs, noninvasiveness, safety, and long-term application $[28,32]$.

Several studies have reported the effect of $\mathrm{RB}$ on reducing pain [28, 33-37]. For example, Farzin Ara et al. showed that $\mathrm{RB}$ reduced pain from $7.2 \pm 3.7$ to $5.9 \pm 1.1$ following orthopedic surgeries [33]. Borzou et al. showed that $\mathrm{RB}$ can help reduce pain and the frequency of analgesic administration in patients after orthopedic surgeries [34]. Furthermore, Borzou et al. showed that RB is an effective method for relieving pain due to hemodialysis vascular needles [28]. Lalegani et al. (2013), Bozorg-Nejad et al., and Park et al. showed that RB can significantly reduce the severity of pain during the dressing of burns [35-37].

Sternotomy site pain is the patients' most common complaint and probably the most severe postoperative pain experienced, which can be associated with increased patient morbidity and mortality [38]. Patients undergoing openheart surgery experience the worst possible pain during coughing and deep breathing, and their pain is inadequately controlled and prevents them from deep breathing and effective coughing despite medicinal interventions such as the administration of nonsteroidal anti-inflammatory medications and opioids [39]. Given the lack of research on the effect of this technique on patients' pain following CABG, the present study was designed and conducted to determine the effect of $\mathrm{RB}$ on post-CABG sternotomy pain control.

\section{Methods}

2.1. Study Design and Participants. This parallel randomized, controlled nonmasked clinical trial was conducted between September 2018 and September 2019 on patients undergoing CABG surgery at Kowsar Hospital, affiliated to Semnan University of Medical Sciences in Iran. Following a preliminary study with ten patients from each group (RB and control), the mean and standard deviation of the severity of pain were found as $1.3 \pm 0.65$ in the RB group and $2 \pm 0.8$ in the control group. Then, taking into account $95 \%$ confidence interval and $80 \%$ test power and using equation $\left(n=\left(\left(z_{1-\alpha / 2}+z_{1-\beta}\right)^{2} \times\left(\delta_{1}{ }^{2}+\delta_{2}{ }^{2}\right)\right) /\left(\mu_{1}-\mu_{2}\right)^{2}\right)$, the sample size was determined as 30 patients per group. Using $G *$ power, the effect size was estimated as 0.96 (means: difference between two independent means). A total of 67 patients entered the study, of whom seven withdrew for various reasons, and the data from 60 patients (30 per group) were ultimately analyzed. The patients who fulfilled the inclusion criteria were included in the study and were then randomly assigned to the groups using random blocks of $\mathrm{A}$ for the experimental group (RB) and B for the control group. Since patients who practice $\mathrm{RB}$ are easily distinguished and the researcher taught the patients how to breathe rhythmically, it was not possible to perform blinding. Figure 1 presents the flow chart of the participants.

The study inclusion criteria were as follows: undergoing elective CABG surgery, age 35-80 years, stable 

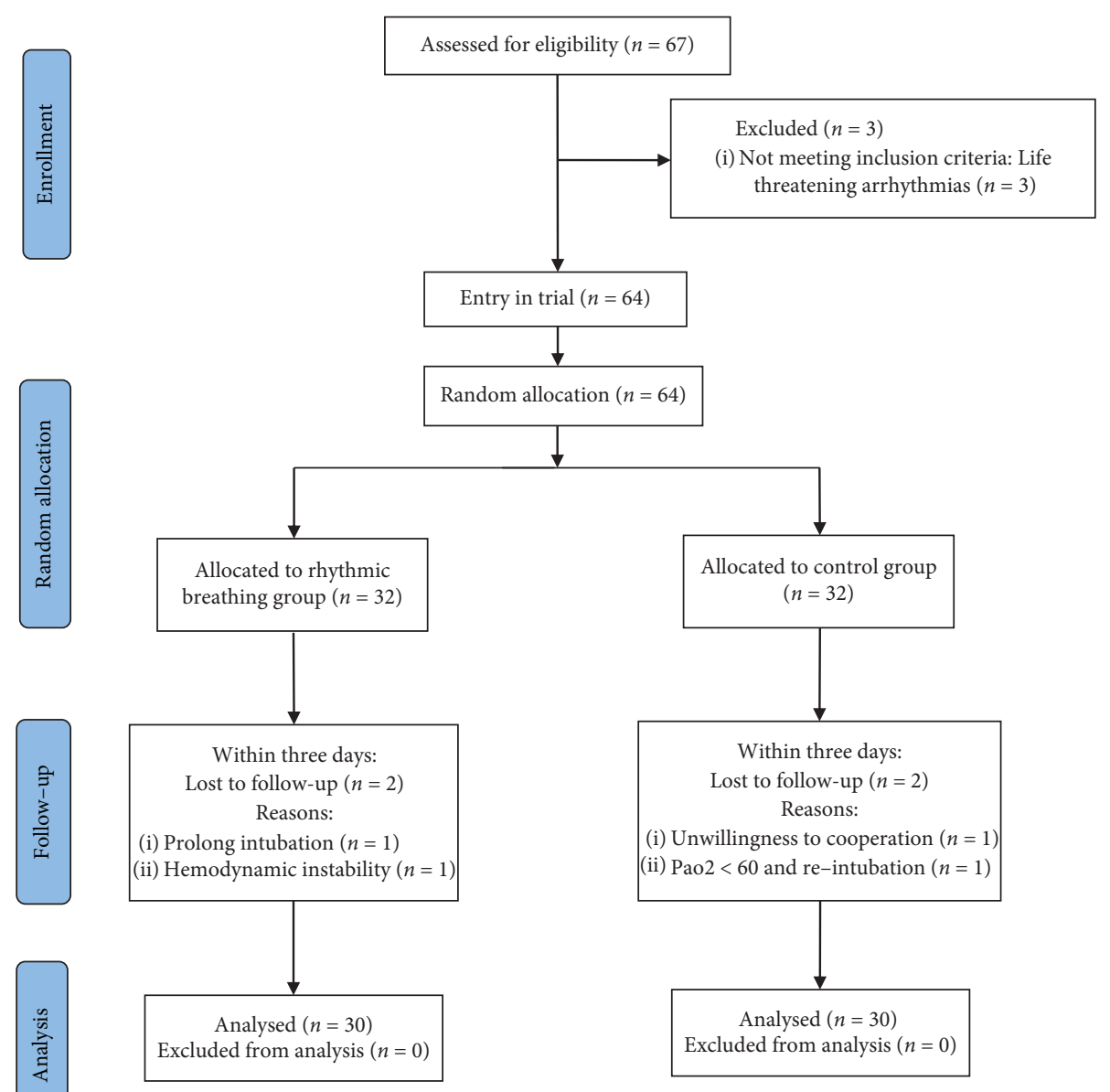

FIgURE 1: CONSORT flowchart of the study.

hemodynamic status (blood pressure $>90 \mathrm{mmHg}$, and $50<$ pulse rate $<110$ ), no previous history of CABG, no lifethreatening arrhythmias, and no use of Cardiopulmonary Bypass (CPB). The exclusion criteria were as follows: having a history of diabetes, prolonged intubation (more than 24 hours after surgery), dependence on inotropic agents for hemodynamic stability after extubation, $\mathrm{PaO}_{2}<60 \mathrm{mmHg}$ without receiving oxygen via the nasal cannula or mask, renal dysfunction before and after surgery, history of chronic pain, and the need for other pain control methods such as music or massage therapy.

2.2. Ethical Considerations. In terms of ethical considerations, the Ethics Committee of Semnan University of Medical Sciences approved the present research (IR.SEMUMS.REC.1397.138). This study was also registered in the Iranian Registry of Clinical Trials (IRCT20120109008665N7). After introducing himself to the patients, the researcher briefed the participants on the research objectives and procedures, assured them of the confidentiality of their information and their right to withdraw from the study at their own discretion and responded to their questions. The subjects then signed written informed consent forms for participation.
2.3. Interventions. $\mathrm{RB}$ technique was performed for the intervention group. RB was individually taught to the intervention group before surgery until they could perform it independently and correctly. The day after surgery, upon gaining full consciousness and hemodynamic stability, the patients were asked to close their eyes in the supine position, inhale through the nose, then hold their breath, and exhale through the mouth, while counting from 1 to 3 in each step. All the patients in the intervention group were trained to focus only on air entry and exit while breathing, and they were asked to perform RB once every five minutes, lasting one minute each time, for 20 minutes (totally four times every 20 minutes) [32]. The patients received supplemental oxygen during the intervention if required. Supervised by the researcher, RB was performed every 12 hours ( 9 a.m. and 9 p.m.) for three consecutive days. The control group received only routine care (opioids, such as morphine) with no additional interventions. The routine care given to both groups was the same.

2.4. Data Collection. Data were collected using a two-part questionnaire. The first part dealt with the patients' demographic details, including age, gender, education, body mass index (BMI), underlying diseases, duration of 
hospitalization before and after surgery, history of smoking and opioid use, amount of opioid injection, on-pump duration, ejection fraction, duration of mechanical ventilation, and the number of grafts and chest tubes. Surgery was performed using a cardiopulmonary pump in both groups. Also, the method of anesthesia, anesthesia medications, and fluid therapy during and after surgery were the same for all the patients. Any changes in routine instructions were recorded by the researcher.

In the second part, the patients' pain score data were collected by the Visual Analog Scale (VAS). Pain was measured at 9 a.m. and 9 p.m. before and after RB performance in both groups for three days. The patients were asked to express their pain severity by choosing a number between 0 (no pain) and 10 (most severe pain). VAS categorizes the severity of pain into four groups: $0=$ no pain, $1-3=$ mild pain, $4-7=$ moderate pain, and $8-10=$ severe pain. In one study, Alghadir et al. confirmed the reliability of VAS with an intraclass correlation coefficient of 0.97 [40]. In the present study, the reliability of VAS was confirmed in a pilot study on ten patients with Cronbach's alpha of 0.94 .

2.5. Statistical Analysis. Data were analyzed with a perprotocol approach in SPSS-19 (SPSS Inc., Chicago, IL, USA) at a significance level of 0.05 . The study data were described, grouped, and compared in absolute and relative frequency tables. The results of the Kolmogorov-Smirnov test confirmed the normal distribution of the data. The independent sample $t$-test was used to compare the two groups in terms of age, BMI, smoking, on-pump duration, ejection fraction, mechanical ventilation, hospitalization before and after surgery, mean severity of pain before and after intervention, difference between the mean values preintervention and postintervention in each group, and the amount of morphine used. The Chi-square test was used to compare the absolute and relative frequencies in terms of the patients' gender, education, drug use, underlying diseases, number of grafts and chest tubes, and pain intensity between the two groups. The repeated-measures analysis of variance was used to assess the effect of time and the interaction effect of group and time on the mean severity of pain three days after surgery.

For analysis of variance with repeated measures, the following statistical presuppositions were examined first: quantitativeness of the dependent variable, elimination of outliers, normal distribution of the dependent variable distribution, and confirmation of sphericity of the groups with Mauchly's statistics, and three factors of intervention (versus control), time point during the day (difference between before and after scores at 9 a.m. and 9 p.m.), and days (first, second, and third) were entered into the analysis.

\section{Results}

3.1. Participants'Characteristics. The present study recruited 60 patients after CABG surgery. The patients' mean age was $61.58 \pm 9.7$ years, and the majority $(80 \%)$ were male. Table 1 presents the demographic and surgery details of the patients in both groups. No significant difference was found between the two groups in terms of demographic and surgery details $(p>0.05)$. One-third of the patients in the intervention group and more than half in the control group had several underlying diseases, and hypertension was the single most frequent underlying disease in them.

3.2. Severity of Pain. The independent $t$-test results showed no significant difference between the two groups in the severity of pain in the first three days after surgery before beginning the intervention, except on the third night $(p>0.05)$. Meanwhile, the severity of pain after the intervention, as measured on both occasions (9 a.m. and 9 p.m.) in all three days, was significantly lower in the RB group compared to the controls $(p<0.05)$ (Table 2, Figure 2$)$. The results of the Chi-square test revealed significant differences between the two groups in terms of the severity of pain (no pain, mild pain, and moderate pain) before and after the intervention $(p<0.05)$. None of the patients in both groups had severe pain (Table 3 ). There were significant differences between the two groups in terms of the mean difference in the severity of pain before and after the intervention $(p<0.05)$ (Table 4$)$. The results of the repeated-measures ANOVA showed a significant difference between the two groups in the mean difference in severity of pain after the intervention, such that the severity of pain was lower in the $\mathrm{RB}$ group compared to the controls. In other words, the intervention reduced the severity of pain significantly over time $(F(1,58)=137.3, p<0.001)$ (Table 5). The mean and standard deviation of the dose of morphine administered was $3.40 \pm 1.97 \mathrm{mg}$ in the RB group and $5.30 \pm 2.57 \mathrm{mg}$ in the control group. The $t$-test results showed no significant difference between the two groups in the dose of morphine administered $(p=0.604)$.

\section{Discussion}

The present findings on the effect of $\mathrm{RB}$ on post-CABG sternotomy pain control confirmed that $\mathrm{RB}$ was effective in reducing the severity of sternotomy pain after surgery in the intervention group. To the best of the authors' knowledge, this is the first study to investigate the effect of RB on postCABG sternotomy pain.

After the intervention, the severity of pain, as measured on both occasions (9 a.m. and 9 p.m.) in three consecutive days following the surgery, was significantly lower in the intervention group compared to the controls. The results of the repeated-measures ANOVA showed a significant difference between the two groups in the mean difference in the severity of pain over the three days, which was lower in the intervention group. In agreement with this result, several studies conducted on the effect of $\mathrm{RB}$ on pain have also shown that $\mathrm{RB}$ can help reduce pain and the number of analgesics administered after surgery $[28,33,34]$. The results of a study conducted in Iran by Farzin Ara et al. (2018) to compare the effect of reciting the word "Allah" and performing $\mathrm{RB}$ on postoperative pain in orthopedic patients showed that, compared to the control group, the group 
TABLE 1: The demographic and surgical-related characteristics of the participants in the rhythmic breathing/control groups.

\begin{tabular}{|c|c|c|c|}
\hline Groups characteristics & $\mathrm{RB}(n=30) N(\%)$ & Control $(n=30) N(\%)$ & $p$ value ${ }^{*}$ \\
\hline $\begin{array}{l}\text { Gender } \\
\text { Male } \\
\text { Female }\end{array}$ & $\begin{array}{c}24(80) \\
6(20) \\
\end{array}$ & $\begin{array}{c}27(90) \\
3(10)\end{array}$ & $X^{2}=1.17,1, p=0.278$ \\
\hline $\begin{array}{l}\text { Level of education } \\
\text { Below high school diploma } \\
\text { Higher education }\end{array}$ & $\begin{array}{r}28(93.3) \\
2(6.7) \\
\end{array}$ & $\begin{array}{r}28(93.3) \\
2(6.7) \\
\end{array}$ & $X^{2}=0.000,1, p=1$ \\
\hline $\begin{array}{l}\text { Opium consumption } \\
\text { Yes } \\
\text { No } \\
\end{array}$ & $\begin{array}{c}9(30) \\
21(70) \\
\end{array}$ & $\begin{array}{l}15(50) \\
15(50) \\
\end{array}$ & $X^{2}=2.50,1, p=0.114$ \\
\hline $\begin{array}{l}\text { Underlying disease }^{a} \\
\text { Yes } \\
\text { No } \\
\end{array}$ & $\begin{array}{l}24(80) \\
6(20) \\
\end{array}$ & $\begin{aligned} & 28(93.3) \\
& 2(6.7) \\
&\end{aligned}$ & $X^{2}=2.30,1, p=0.129$ \\
\hline $\begin{array}{l}\text { Number of grafts } \\
2 \\
3 \\
\geq 4\end{array}$ & $\begin{aligned} 1 & (3.3) \\
10 & (33.3) \\
19 & (63.4)\end{aligned}$ & $\begin{aligned} 1 & (3.3) \\
9 & (30) \\
20 & (66.7)\end{aligned}$ & $X^{2}=0.07,2, p=0.962$ \\
\hline $\begin{array}{l}\text { Number of chest tubes } \\
2 \\
3\end{array}$ & $\begin{array}{c}24(80) \\
6(20) \\
\end{array}$ & $\begin{array}{c}27(90) \\
3(10) \\
\end{array}$ & $X^{2}=1.17,1, p=0.278$ \\
\hline & $($ Mean \pm SD $)$ & $($ Mean \pm SD $)$ & $p$ value $^{* *}$ \\
\hline $\begin{array}{l}\text { Age (years) } \\
\text { BMI (kg/m2) } \\
\text { Smoking (butts/day) } \\
\text { On-pump duration (minute) } \\
\text { Ejection fraction (\%) } \\
\text { Medical ventilation time (hour) } \\
\text { Duration of preoperative hospitalization (day) } \\
\text { Duration of postoperative hospitalization (day) }\end{array}$ & $\begin{array}{c}60.80 \pm 9.4 \\
26.73 \pm 4.4 \\
4.73 \pm 10.9 \\
109.70 \pm 25.3 \\
46.50 \pm 11.2 \\
9.63 \pm 4.2 \\
4.5 \pm 2 \\
5.67 \pm 1.4\end{array}$ & $\begin{array}{l}62.37 \pm 10.1 \\
26.03 \pm 4.1 \\
9.83 \pm 15.3 \\
111.90 \pm 28 \\
50.83 \pm 5.5 \\
10.93 \pm 4.3 \\
5.53 \pm 3.2 \\
6.03 \pm 1.3\end{array}$ & $\begin{array}{c}t(58)=-0.61, p=0.539 \\
t(58)=0.63, p=0.526 \\
t(52.41)=-1.48, p=0.204 \\
t(58)=-0.32, p=0.751 \\
t(42.51)=-1.89, p=0.065 \\
t(58)=-1.16, p=0.249 \\
t(49.2)=-1.46, p=0.150 \\
t(58)=-1.01, p=0.315\end{array}$ \\
\hline
\end{tabular}

RB: rhythmic breathing; BMI: body mass index; ${ }^{*}$ Chi-square test; ${ }^{* *}$ independent $t$-test. ${ }^{a}$ Including: hypertension, hyperlipidemia.

TABLE 2: The comparisons of mean scores of the pain severity in the RB and control groups.

\begin{tabular}{|c|c|c|c|c|c|c|c|}
\hline Day & Hours & Measurement times & Groups & Mean \pm SD & Min & Max & value* \\
\hline \multirow{7}{*}{ Fist day } & \multirow{3}{*}{9 a.m. } & Before intervention & $\begin{array}{c}\mathrm{RB} \\
\text { Control }\end{array}$ & $\begin{array}{l}2.37 \pm 0.99 \\
2.30 \pm 1.39\end{array}$ & $\begin{array}{l}1 \\
1\end{array}$ & $\begin{array}{l}5 \\
6\end{array}$ & $t(52.6)=0.213, p=0.832$ \\
\hline & & \multirow{2}{*}{ After intervention } & $\mathrm{RB}$ & $1.07 \pm 0.64$ & 0 & 3 & \multirow{2}{*}{$t(58)=-2.90, p=0.005$} \\
\hline & & & Control & $1.50 \pm 0.5$ & 1 & 2 & \\
\hline & \multirow{4}{*}{9 p.m. } & \multirow{2}{*}{ Before intervention } & $\mathrm{RB}$ & $2.10 \pm 0.84$ & 1 & 4 & \multirow{2}{*}{$t(58)=0.91, p=0.363$} \\
\hline & & & Control & $1.90 \pm 0.84$ & 1 & 4 & \\
\hline & & \multirow{2}{*}{ After intervention } & $\mathrm{RB}$ & $0.87 \pm 0.50$ & 0 & 2 & \multirow{2}{*}{$t(57.2)=-4.78, p<0.001$} \\
\hline & & & Control & $1.53 \pm 0.57$ & 1 & 3 & \\
\hline \multirow{8}{*}{ Second day } & \multirow{4}{*}{9 a.m. } & \multirow{2}{*}{ Before intervention } & $\mathrm{RB}$ & $1.90 \pm 0.54$ & 1 & 3 & \multirow{2}{*}{$t(40)=-040, p=0.687$} \\
\hline & & & Control & $2 \pm 1.23$ & 1 & 5 & \\
\hline & & \multirow{2}{*}{ After intervention } & $\mathrm{RB}$ & $0.83 \pm 0.46$ & 0 & 2 & \multirow{2}{*}{$t(53.3)=-5.17, p<0.001$} \\
\hline & & & Control & $1.57 \pm 0.62$ & 1 & 3 & \\
\hline & \multirow{4}{*}{9 p.m. } & Before intervention & $\mathrm{RB}$ & $1.97 \pm 0.49$ & 1 & 3 & \multirow{4}{*}{$\begin{array}{l}t(54.3)=1.58, p=0.119 \\
t(55.5)=-4.91, p<0.001\end{array}$} \\
\hline & & Detore interventionte & Control & $1.73 \pm 0.64$ & 1 & 3 & \\
\hline & & \multirow{2}{*}{ After intervention } & $\mathrm{RB}$ & $0.97 \pm 0.49$ & 0 & 2 & \\
\hline & & & Control & $1.67 \pm 0.60$ & 1 & 3 & \\
\hline \multirow{8}{*}{ Third day } & \multirow{4}{*}{9 a.m. } & \multirow{2}{*}{ Before intervention } & $\mathrm{RB}$ & $1.73 \pm 0.58$ & 1 & 3 & \multirow{2}{*}{$t(58)=1.78, p=0.079$} \\
\hline & & & Control & $1.47 \pm 0.57$ & 1 & 3 & \\
\hline & & \multirow{2}{*}{ After intervention } & $\mathrm{RB}$ & $0.70 \pm 0.53$ & 0 & 2 & \multirow{2}{*}{$t(58)=-5.46, p<0.001$} \\
\hline & & & Control & $1.43 \pm 0.50$ & 1 & 2 & \\
\hline & \multirow{4}{*}{9 p.m. } & \multirow{2}{*}{ Before intervention } & $\mathrm{RB}$ & $1.77 \pm 0.62$ & 1 & 3 & \multirow{2}{*}{$t(58)=2.27, p=0.027$} \\
\hline & & & Control & $1.43 \pm 0.50$ & 1 & 2 & \\
\hline & & \multirow{2}{*}{ After intervention } & $\mathrm{RB}$ & $0.70 \pm 0.53$ & 0 & 2 & \multirow{2}{*}{$t(58)=-5.46, p<0.001$} \\
\hline & & & Control & $1.43 \pm 0.50$ & 1 & 2 & \\
\hline
\end{tabular}

RB : rhythmic breathing; SD: standard deviation; Min : minimum; Max : maximum; *independent $t$-test. 


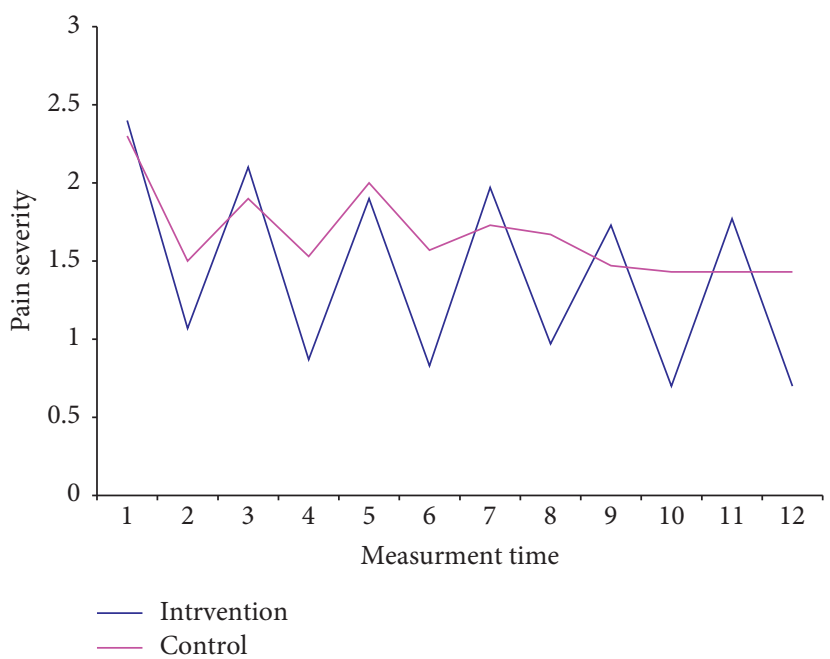

Figure 2: Mean scores of the pain severity after CABG.

TABLE 3: The comparison of the patients in the RB and control groups in terms of pain severity.

\begin{tabular}{|c|c|c|c|c|c|c|c|}
\hline Day & Hours & Measurement times & Groups & No pain & Mild pain & Moderate pain & $p$ value* \\
\hline \multirow{8}{*}{ Fist day } & \multirow{4}{*}{9 a.m. } & \multirow{2}{*}{ Before intervention } & $\mathrm{RB}$ & 0 & 25 & 5 & \multirow{2}{*}{$X^{2}=0.109,1, p=0.741$} \\
\hline & & & Control & 0 & 24 & 6 & \\
\hline & & \multirow{2}{*}{ After intervention } & $\mathrm{RB}$ & 4 & 26 & 0 & \multirow{2}{*}{$X^{2}=4.21,1, p=0.040$} \\
\hline & & & Control & 0 & 30 & 0 & \\
\hline & \multirow{4}{*}{9 p.m. } & \multirow{2}{*}{ Before intervention } & $\mathrm{RB}$ & 0 & 27 & 3 & \multirow{2}{*}{$X^{2}=1.05,1, p=0.305$} \\
\hline & & & Control & 0 & 29 & 1 & \\
\hline & & \multirow{2}{*}{ After intervention } & $\mathrm{RB}$ & 6 & 24 & 0 & \multirow{2}{*}{$X^{2}=6.55,1, p=0.010$} \\
\hline & & & Control & 0 & 30 & 0 & \\
\hline \multirow{8}{*}{ Second day } & \multirow{4}{*}{9 a.m. } & \multirow{2}{*}{ Before intervention } & $\mathrm{RB}$ & 0 & 30 & 0 & \multirow{2}{*}{$X^{2}=5.36,1, p=0.052$} \\
\hline & & & Control & 0 & 25 & 5 & \\
\hline & & \multirow{2}{*}{ After intervention } & $\mathrm{RB}$ & 6 & 24 & 0 & \multirow{2}{*}{$X^{2}=6.55,1, p=0.010$} \\
\hline & & & Control & 0 & 30 & 0 & \\
\hline & \multirow{4}{*}{9 p.m. } & \multirow{2}{*}{ Before intervention } & $\mathrm{RB}$ & 0 & 30 & 0 & \multirow{2}{*}{-} \\
\hline & & & Control & 0 & 30 & 0 & \\
\hline & & \multirow{2}{*}{ After intervention } & $\mathrm{RB}$ & 4 & 26 & 0 & \multirow{2}{*}{$X^{2}=4.21,1, p=0.040$} \\
\hline & & & Control & 0 & 30 & 0 & \\
\hline \multirow{8}{*}{ Third day } & \multirow{4}{*}{9 a.m. } & \multirow{2}{*}{ Before intervention } & $\mathrm{RB}$ & 0 & 30 & 0 & \multirow[b]{2}{*}{-} \\
\hline & & & Control & 0 & 30 & 0 & \\
\hline & & \multirow{2}{*}{ After intervention } & $\mathrm{RB}$ & 10 & 20 & 0 & \multirow{2}{*}{$X^{2}=11.80,1, p=0.001$} \\
\hline & & & Control & 0 & 30 & 0 & \\
\hline & \multirow{4}{*}{9 p.m. } & \multirow{2}{*}{ Before intervention } & $\mathrm{RB}$ & 0 & 30 & 0 & \multirow{2}{*}{ 一 } \\
\hline & & & Control & 0 & 30 & 0 & \\
\hline & & \multirow{2}{*}{ After intervention } & $\mathrm{RB}$ & 10 & 20 & 0 & \multirow{2}{*}{$X^{2}=11.80,1, p=0.001$} \\
\hline & & & Control & 0 & 30 & 0 & \\
\hline
\end{tabular}

RB: rhythmic breathing; ${ }^{*}$ Chi-square (linear-by-linear association).

reciting Allah, followed by the group performing $\mathrm{RB}$, had lower mean severities of pain. They concluded that both methods can be used to reduce pain after orthopedic surgery [33]. The results obtained by Borzou et al. in Malayer, Iran, also showed the effectiveness of RB on the severity of pain after orthopedic surgery and the dose of analgesics administered [34]. The results obtained by Borzou et al. in Hamadan, Iran, showed the effect of $\mathrm{RB}$ in reducing the severity of pain caused by hemodialysis vascular needles, as well [28]. Lalegani et al., Bozorg-Nejad et al., and Park et al. confirmed the positive effect of $\mathrm{RB}$ on pain reduction during redressing of burns [35-37]. The results reported by Marsdin et al. in their study titled "The Effect of Audio and Video Distractions on Reducing Lithotripsy Pain" showed that there was a significant difference in the perception of pain and distress between the distraction and control groups [41]. The results obtained by Esmaeili et al. and Valizadeh et al. on the effect of regular breathing exercise and music on the pain of inserting intravenous (IV) lines during blood infusion showed that both these methods significantly reduced children's pain, although music was more effective than breathing exercise $[42,43]$. Bageriyan et al. compared the effects of bubbling and regular breathing exercise on reducing venipuncture pain in school children admitted to the 
TABLE 4: The comparison of mean differences scores of the pain severity before and after intervention in the RB and control groups.

\begin{tabular}{|c|c|c|c|c|c|c|}
\hline Day & Measurement times & Groups & Mean \pm SD & Min & Max & $p$ value $^{*}$ \\
\hline \multirow{3}{*}{ Fist day } & 9 a.m. & $\begin{array}{c}\mathrm{RB} \\
\text { Control }\end{array}$ & $\begin{array}{l}1.3 \pm 0.59 \\
0.8 \pm 1.06\end{array}$ & $\begin{array}{l}1 \\
0\end{array}$ & $\begin{array}{l}3 \\
4\end{array}$ & $t(45.5)=2.24, p=0.028$ \\
\hline & \multirow[b]{2}{*}{9 p.m. } & $\mathrm{RB}$ & $1.23 \pm 0.56$ & 1 & 3 & \multirow{2}{*}{$t(58)=5.67, p<0.001$} \\
\hline & & Control & $0.36 \pm 0.61$ & 0 & 2 & \\
\hline \multirow{4}{*}{ Second day } & \multirow{2}{*}{9 a.m. } & $\mathrm{RB}$ & $1.06 \pm 0.25$ & 1 & 2 & \multirow{2}{*}{$t(32.9)=3.45, p=0.002$} \\
\hline & & Control & $0.43 \pm 0.97$ & 0 & 3 & \\
\hline & \multirow{2}{*}{9 p.m. } & $\mathrm{RB}$ & $1 / 0 \pm 0.0$ & 1 & 1 & \multirow{2}{*}{$t(29)=20.15, p<0.001$} \\
\hline & & Control & $0.06 \pm 0.25$ & 0 & 1 & \\
\hline \multirow{4}{*}{ Third day } & \multirow{2}{*}{9 a.m. } & $\mathrm{RB}$ & $1.03 \pm 0.18$ & 1 & 2 & \multirow{2}{*}{$t(58)=21.2, p<0.001$} \\
\hline & & Control & $0.03 \pm 0.18$ & 0 & 1 & \\
\hline & \multirow{2}{*}{9 p.m. } & $\mathrm{RB}$ & $1.06 \pm 0.25$ & 1 & 2 & \multirow{2}{*}{$t(29)=23, p<0.001$} \\
\hline & & Control & $0.0 \pm 0.0$ & 0 & 0 & \\
\hline
\end{tabular}

RB : rhythmic breathing; SD: standard deviation; Min: minimum; Max: maximum; *independent $t$-test.

TABLE 5: Results of repeated-measures ANOVA in terms of pain severity in the RB and control groups.

\begin{tabular}{|c|c|c|c|c|c|c|}
\hline Source of change & Variables & Sum of squares & $\mathrm{df}^{*}$ & Mean squares & $\mathrm{F}$ & $p$ value \\
\hline \multirow{3}{*}{ Within-subjects } & Time $^{a}$ & 13.10 & 1 & 13.10 & 10.56 & 0.002 \\
\hline & Time $\times$ group & 3.66 & 1 & 3.66 & 2.95 & 0.09 \\
\hline & Error & 71.90 & 58 & 1.24 & & \\
\hline \multirow{3}{*}{ Between-subject } & Constant & 176.4 & 1 & 176.4 & 387.05 & $<0.001$ \\
\hline & Group & 62.50 & 1 & 62.50 & 137.13 & $<0.001^{* *}$ \\
\hline & Error & 26.43 & 58 & 0.456 & & \\
\hline
\end{tabular}

${ }^{*}$ Lower bound; ${ }^{* *}$ adjusted for time, and interaction of time and group. Time ${ }^{a}$ : day 1 (T1, T2); day $2(T 1, T 2)$; and day $3(T 1, T 2)$. T1 indicates the difference in pain severity between before and after the intervention at 9 a.m., and $T 2$ indicates the difference in pain severity between before and after the intervention at 9 p.m..

thalassemia center of Kerman, Iran. Their results showed no significant difference between the two groups in the mean score of pain [44]. The results of a study conducted by Vakilian and Keramat to compare the effects of aromatherapy with lavender and breathing techniques on reducing labor pain showed that the mean change in the severity of pain before and after the intervention was significantly different in the breathing technique group [45].

Nevertheless, the results obtained by Slade showed that these techniques are less effective than expected in reducing pain [46]. According to Mehdizadeh, most studies have highlighted the beneficial and positive effects of breathing and neuromuscular techniques, but there are reports indicating their ineffectiveness [47], including one by Pugh et al., which argued that breathing techniques exhaust the mother and delay childbirth [48].

The results showed no significant difference between the two groups in the dose of morphine administered $(1.97 \mathrm{mg}$ in the RB group and $2.57 \mathrm{mg}$ in the control group), but this difference was clinically significant. Other studies reported a significant difference between their intervention and control groups in the number of analgesics received after surgery $[33,34]$, which disagrees with the present findings. This disagreement can be attributed to the different target populations, patients' gender, and type of intervention or surgery.

In the present study, the severity of pain was significantly higher in the RB group than the control group at 9 p.m., three days before the intervention, but after the intervention, a significant reduction was observed in the severity of pain in the $\mathrm{RB}$ group compared to the controls. This important finding is indicative of the effect of $\mathrm{RB}$ on reducing pain, which was also confirmed by the repeated-measures ANOVA results.

The results of pain intensity in patients in both groups also revealed that the pain intensity in the RB group significantly decreased after the intervention compared to that in the control group at 9 a.m. and 9 p.m. for three consecutive days. According to the results, although the effect of time on reducing patients' pain intensity should not be ignored, the intervention (RB) significantly affected patients' pain intensity.

According to the researchers, it is necessary to consider factors affecting the perception of the severity of pain. The nature and severity of postoperative pain depend on the size and amount of incision and type of surgery. In addition, the perception of pain depends on ethnicity, culture, beliefs, personal experience of pain, and personality [49]. The factors affecting pain in patients undergoing CABG include the duration of $\mathrm{CPB}$, gender, age (less than 60 years), duration of surgery (more than two hours), and surgery site (thoracic surgery) [16]. Not much evidence supports that the duration of $\mathrm{CPB}<60$ minutes reduces pain. Nonetheless, the release of various cytokines (known as proinflammatory mediators) caused by CPB contributes to pain [50]. Further studies are recommended to further investigate these items.

4.1. Study Limitations. The main limitation of the present research included the reluctance of the patients to follow the 
instructions provided for performing the breathing exercises owing to their improper psychological status. Some measures were thus taken to encourage them to cooperate. A natural limitation of the present study was also associated with the subjective nature of pain, which caused differences in the degree of pain reported by different individuals because pain severity is a patient-reported outcome. The unicenter type of this study and its small sample constituted other limitations, which restricts the external validity of the findings and prohibits their generalizability to other centers. It is recommended that further research be performed with larger samples and more prolonged follow-ups to obtain more accurate results on the effects of rhythmic breathing on pain after CABG with sternotomy.

\section{Conclusions}

The results confirmed that $R B$ is effective in reducing the severity of sternotomy pain after CABG surgery. Given the importance of the management of pain as the fifth vital sign and to prevent the side-effects and problems caused by the lack of proper pain control, especially in patients after CABG, RB can be recommended as a simple, safe, and inexpensive method in the form of an independent nursing activity in conjunction with other medical measures for reducing the severity of pain in patients after CABG surgery.

\section{Data Availability}

The datasets used and/or analyzed during the current study are available from the corresponding author on reasonable request.

\section{Ethical Approval}

This study was approved by the Ethics Committee of Semnan University of Medical Sciences (approval code: IR.SEMUMS.REC.1397.138).

\section{Consent}

Informed written consent was obtained from each participant.

\section{Disclosure}

All the authors have read and approved the final manuscript.

\section{Conflicts of Interest}

The authors declare that there are no conflicts of interest regarding the publication of this paper.

\section{Authors' Contributions}

$\mathrm{HB}, \mathrm{MK}$, and AE contributed to the conception and design of the study and the study protocol. MK and HB managed the running of the study. $\mathrm{HB}$ and $\mathrm{AE}$ conducted data analysis and all authors helped with data interpretation. MK and $\mathrm{HB}$ wrote this manuscript. All authors read and approved the final version of the manuscript.

\section{Acknowledgments}

The present study was extracted from a master thesis on critical care nursing at Semnan University of Medical Sciences and approved as a research project by the university (Code: 1455). The authors would like to express their sincere gratitude to the health center authorities, including Dr. Ghods, and all the university authorities for their financial support and the permission they granted to perform this study. Semnan University of Medical Sciences supported this study with a postgraduate grant (no. 1455).

\section{References}

[1] E. Panagopoulou, A. Montgomery, and A. Benos, "Quality of life after coronary artery bypass grafting: evaluating the influence of preoperative physical and psychosocial functioning," Journal of Psychosomatic Research, vol. 60, no. 6, pp. 639-644, 2006.

[2] R. S. D’Agostino, J. P. Jacobs, V. Badhwar et al., “The society of thoracic surgeons adult cardiac surgery database: 2018 update on outcomes and quality," The Annals of Thoracic Surgery, vol. 105, no. 1, pp. 15-23, 2018.

[3] S. R. Borzou, S. Amiri, M. Salavati, A. R. Soltanian, and G. Safarpoor, "Effects of the first phase of cardiac rehabilitation training on self-efficacy among patients undergoing coronary artery bypass graft surgery," The Journal of Tehran University Heart Center, vol. 13, no. 3, pp. 126-131, 2018.

[4] G. Babaee, M. Keshavarz, and M. Shaigan, "Effect of health education program on quality of life in patients undergoing coronary artery bypass surgery," Acta Medica Iranica, vol. 45, no. 1, pp. 69-75, 2007.

[5] T. Montrief, A. Koyfman, and B. Long, "Coronary artery bypass graft surgery complications: a review for emergency clinicians," The American Journal of Emergency Medicine, vol. 36, no. 12, pp. 2289-2297, 2018.

[6] M. Kowalewski, W. Pawliszak, P. G. Malvindi et al., "Offpump coronary artery bypass grafting improves short-term outcomes in high-risk patients compared with on-pump coronary artery bypass grafting: meta-analysis," The Journal of Thoracic and Cardiovascular Surgery, vol. 151, no. 1, pp. 6077, 2016.

[7] S. M. A. Hussain and A. Harky, "Complications of coronary artery bypass grafting," International Journal of Medical Reviews, vol. 6, no. 1, pp. 1-5, 2019.

[8] B. Indja, M. Seco, R. Seamark et al., "Neurocognitive and psychiatric issues post cardiac surgery," Heart, Lung and Circulation, vol. 26, no. 8, pp. 779-785, 2017.

[9] E. Aguayo, R. Lyons, Y.-Y. Juo et al., "Impact of new-onset postoperative depression on readmission outcomes after surgical coronary revascularization," Journal of Surgical Research, vol. 233, pp. 50-56, 2019.

[10] A. Jahangirifard, M. Razavi, Z. H. Ahmadi, and M. Forozeshfard, "Effect of TENS on postoperative pain and pulmonary function in patients undergoing coronary artery bypass surgery," Pain Management Nursing, vol. 19, no. 4, pp. 408-414, 2018.

[11] J. J. Fibla, L. Molins, J. M. Mier, J. Hernandez, and A. Sierra, "A randomized prospective study of analgesic quality after thoracotomy: paravertebral block with bolus versus 
continuous infusion with an elastomeric pump $\dagger$," European Journal of Cardio-Thoracic Surgery, vol. 47, no. 4, pp. 631-635, 2015.

[12] A. Fiorelli, F. Morgillo, R. Milione et al., "Control of postthoracotomy pain by transcutaneous electrical nerve stimulation: effect on serum cytokine levels, visual analogue scale, pulmonary function and medication," European Journal of Cardio-Thoracic Surgery, vol. 41, no. 4, pp. 861-868, 2012.

[13] C. J. Dunwoody, D. A. Krenzischek, C. Pasero, J. P. Rathmell, and R. C. Polomano, "Assessment, physiological monitoring, and consequences of inadequately treated acute pain," Journal of PeriAnesthesia Nursing, vol. 23, no. 1, pp. S15-S27, 2008.

[14] B. Bordoni, F. Marelli, B. Morabito, B. Sacconi, and P. Severino, "Post-sternotomy pain syndrome following cardiac surgery: case report," Journal of Pain Research, vol. 10, pp. 1163-1169, 2017.

[15] M. A. C. D. Costa, C. A. Trentini, M. D. Schafranski, O. Pipino, R. Z. Gomes, and E. S. D. S. Reis, "Factors associated with the development of chronic post-sternotomy pain: a case-control study," Revista Brasileira de Cirurgia Cardiovascular, vol. 30, no. 5, pp. 552-556, 2015.

[16] J. Cogan, "Pain management after cardiac surgery," Seminars in Cardiothoracic and Vascular Anesthesia, vol. 14, no. 3, pp. 201-204, 2010.

[17] A. Konstantatos, A. J. Silvers, and P. S. Myles, "Analgesia best practice after cardiac surgery," Anesthesiology Clinics, vol. 26, no. 3, pp. 591-602, 2008.

[18] P. Lahtinen, H. Kokki, and M. Hynynen, "Pain after cardiac surgery," Anesthesiology, vol. 105, no. 4, pp. 794-800, 2006.

[19] B. L. Erstad, K. Puntillo, H. C. Gilbert et al., "Pain management principles in the critically ill," Chest, vol. 135, no. 4, pp. 1075-1086, 2009.

[20] J. Boscarino, X. Zhang, S. Yan, J. Gorman, S. Hoffman, and L. Zhang, "Perioperative hyperglycemia is associated with postoperative neurocognitive disorders after cardiac surgery," Neuropsychiatric Disease and Treatment, vol. 10, pp. 361-370, 2014.

[21] A. S. Hamlin and T. M. Robertson, "Pain and complementary therapies," Critical Care Nursing Clinics of North America, vol. 29, no. 4, pp. 449-460, 2017.

[22] K. L. Rice, J. Castex, M. Redmond, J. Burton, J.-W. Guo, and S. L. Beck, "Bundling interventions to enhance pain care quality (BITE pain) in medical surgical patients," Ochsner Journal, vol. 19, no. 2, pp. 77-95, 2019.

[23] A. Bagnasco, E. Pezzi, F. Rosa, L. Fornonil, and L. Sasso, "Distraction techniques in children during venipuncture: an Italian experience," Journal of Preventive Medicine and $\mathrm{Hy}$ giene, vol. 53, no. 1, pp. 44-48, 2012.

[24] A. Kohl, W. Rief, and J. A. Glombiewski, "Acceptance, cognitive restructuring, and distraction as coping strategies for acute pain," The Journal of Pain, vol. 14, no. 3, pp. 305-315, 2013.

[25] K. M. Malloy and L. S. Milling, "The effectiveness of virtual reality distraction for pain reduction: a systematic review," Clinical Psychology Review, vol. 30, no. 8, pp. 1011-1018, 2010.

[26] R. P. Brown, P. L. Gerbarg, and F. Muench, "Breathing practices for treatment of psychiatric and stress-related medical conditions," Psychiatric Clinics of North America, vol. 36, no. 1, pp. 121-140, 2013.

[27] F. Rafii, F. Mohammadi-Fakhar, and R. Jamshidi Orak, "Effectiveness of jaw relaxation for burn dressing pain: randomized clinical trial," Pain Management Nursing, vol. 15, no. 4, pp. 845-853, 2014.
[28] S. R. Borzou, S. Akbari, G. H. Falahynia, and H. Mahjoub, "Effect of rhythmic breathing on pain intensity during insertion of vascular needles in hemodialysis patients," Hayat, vol. 19, no. 4, pp. 6-14, 2014.

[29] R. P. Brown and P. L. Gerbarg, "Sudarshan kriya yogic breathing in the treatment of stress, anxiety, and depression: Part I-neurophysiologic model," The Journal of Alternative and Complementary Medicine, vol. 11, no. 1, pp. 189-201, 2005.

[30] T. Hoseini, F. Golaghaie, and S. Khosravi, "Comparison of two distraction methods on venipuncture pain in children," Journal of Arak University of Medical Sciences, vol. 22, no. 3, pp. 27-35, 2019.

[31] D. Songer, "Psychotherapeutic approaches in the treatment of pain," Psychiatry, vol. 2, no. 5, pp. 19-24, 2005.

[32] A. Mohammadpour, M. Basiri, and N. Saber, "The effect of rhythmic breathing on the cardiorespiratory parameters in Acute Coronary Syndrome patients admitted at CCU," Journal of Sabzevar University of Medical Sciences, vol. 23, no. 2, pp. 377-385, 2016.

[33] F. Farzin Ara, M. Zare, M. Mousavi Garmaroudi, S. Behnam Vashani, and S. Talebi, "Comparative study of the effect of allah's recitation and rhythmic breathing on postoperative pain in orthopedic patients," Anesthesiology and Pain (JAP), vol. 9, no. 1, pp. 68-78, 2018.

[34] S. Borzou, G. Felegari, and B. Turkman, "Survey effect of rhythmic breathing on the intensity of pain in the post orthopedic surgery patients," Scientific Journal of Kurdistan University of Medical Sciences, vol. 6, no. 23, pp. 6-10, 2002.

[35] H. Lalegani, A. Safar, and A. Safdari, "The effect of breathing techniques on pain intensity of burn dressing," Journal of Clinical Nursing, vol. 2, no. 4, pp. 61-68, 2014.

[36] M. Bozorg-Nejad, H. Azizkhani, F. Mohaddes Ardebili, F. Mousavi, F. Manafi, and A. F. Hosseini, "The effect of rhythmic breathing on pain of dressing change in patients with burns referred to ayatollah mousavi hospital," World Journal of Plastic Surgery, vol. 7, no. 1, pp. 51-57, 2018.

[37] E. Park, H. Oh, and T. Kim, "The effects of relaxation breathing on procedural pain and anxiety during burn care," Burns, vol. 39, no. 6, pp. 1101-1106, 2013.

[38] R. Hughes and F. Gao, "Pain control for thoracotomy," Continuing Education in Anaesthesia Critical Care \& Pain, vol. 5, no. 2, pp. 56-60, 2005.

[39] M. Chailler, J. Ellis, A. Stolarik, and K. Woodend, "Cold therapy for the management of pain associated with deep breathing and coughing post-cardiac surgery," Canadian journal of cardiovascular nursing = Journal canadien en soins infirmiers cardio-vasculaires, vol. 20, no. 2, pp. 18-24, 2010.

[40] A. Alghadir, S. Anwer, A. Iqbal, and Z. Iqbal, "Test-retest reliability, validity, and minimum detectable change of visual analog, numerical rating, and verbal rating scales for measurement of osteoarthritic knee pain," Journal of Pain Research, vol. 11, pp. 851-856, 2018.

[41] E. Marsdin, J. G. Noble, J. M. Reynard, and B. W. Turney, "Audiovisual distraction reduces pain perception during shockwave lithotripsy," Journal of Endourology, vol. 26, no. 5, pp. 531-534, 2012.

[42] K. Esmaeili, S. Sadeghy, S. Iranfar, and P. Abasi, "The Comparison of the effect of music and rhythmic breathing techniques on pain severity of intravenous cannulation during blood transfusion," Journal of Kermanshah University of Medical Sciences, vol. 12, no. 2, pp. 129-139, 2008.

[43] F. Valizadeh, M. Shahabi, and Y. Mehrabi, "A comparison the two methods effect on divagation of mind: music Hay-Ho 
Rhythmic breathing technique," Yafte, vol. 6, no. 3, pp. 43-51, 2004.

[44] S. Bageriyan, F. Borhani, and A. Abaszadeh, "The effect of non-pharmacologic pain management methods for venipuncture pain in school aged children in the center for Thalassemia in the city of Kerman," Nursing and Midwifery Studies, vol. 10, no. 6, pp. 741-748, 2013.

[45] K. Vakilian and A. Keramat, "The effect of the breathing technique with and without aromatherapy on the length of the active phase and second stage of labor," Nursing and Midwifery Studies, vol. 1, no. 3, pp. 115-119, 2013.

[46] P. Slade, S. A. MacPherson, A. Hume, and M. Maresh, "Expectations, experiences and satisfaction with labour," British Journal of Clinical Psychology, vol. 32, no. 4, pp. 469-483, 1993.

[47] A. Mehdizadeh, F. Roosta, S. Chaichian, and R. Alaghehbandan, "Evaluation of the impact of birth preparation courses on the health of the mother and the newborn," American Journal of Perinatology, vol. 22, no. 01, pp. 7-9, 2005.

[48] L. C. Pugh, R. A. Milligan, S. Gray, and O. L. Strickland, "First stage labor management: an examination of patterned breathing and fatigue," Birth, vol. 25, no. 4, pp. 241-245, 1998.

[49] M. Perry, K. Baumbauer, E. E. Young, S. G. Dorsey, J. Y. Taylor, and A. R. Starkweather, "The influence of race, ethnicity and genetic variants on postoperative pain intensity: an integrative literature review," Pain Management Nursing, vol. 20, no. 3, pp. 198-206, 2019.

[50] K. M. Kulmatycki and F. Jamali, "Drug disease interactions: role of inflammatory mediators in pain and variability in analgesic drug response," Journal of Pharmacy \& Pharmaceutical Sciences, vol. 10, no. 4, pp. 554-566, 2007. 